Original Research Article

\title{
Computer assisted learning module in experimental pharmacology for medical students: introduction and evaluation
}

\author{
Sunita Singh ${ }^{1 *}$, Harshwarshan $^{2}$, Vivek Singh ${ }^{3}$, Barakha Gupta $^{4}$
}

\begin{abstract}
${ }^{1}$ Department of Pharmacology, North DMC Medical College \& Hindu Rao Hospital, New Delhi, India

${ }^{2}$ Department of Pharmacology, G.S. Medical College, Pilkhuwa, Hapur, Uttar Pradesh, India ${ }^{3}$ Department of Pharmacology, Saraswathi Institute of Medical Sciences, Hapur, Uttar Pradesh, India

${ }^{4}$ Department of Forensic Medicine, Saraswathi Institute of Medical Sciences, Hapur, Uttar Pradesh, India
\end{abstract}

Received: 02 October 2018

Revised: 03 November 2018

Accepted: 29 November 2018

*Correspondence to:

Dr. Sunita Singh,

Email: drsunitakr@gmail.com

Copyright: (C) the author(s), publisher and licensee Medip Academy. This is an openaccess article distributed under the terms of the Creative Commons Attribution NonCommercial License, which permits unrestricted noncommercial use, distribution, and reproduction in any medium, provided the original work is properly cited.

\begin{abstract}
Background: Animal experiments have been restricted due to strict Committee for the Purpose of Control and Supervision of Experiments on Animals (CPCSEA) rules and regulations for animal procurement and experimentation. At present, teaching is done by showing cards with tracings. This helps in the development of cognitive domain only. There is a need to change the traditional passive learning methodologies to an active technology based experimental learning methodology. Present educational interventional study is aimed at enhancing learning and making teaching interactive and interesting by introducing Computer Assisted Learning (CAL). Objectives of the study are to assess and evaluate the learning outcome of two methods (teaching by showing cards and computer assisted) in experimental Pharmacology and to assess the perception of students and faculty towards implementation of CAL.

Methods: The study was conducted at Sarawathi Institute of Medical Sciences, Hapur, UP, India. A departmental meeting was organized to sensitize the faculty members. Test and feedback questionnaire were prepared. Participants were divided into two groups. One group was taught by cards and another by CAL. For second experiment students cross over was done. Students were assessed by posttest analysis. Feedback from the faculty and students were taken and analyzed.

Results: There was improvement in knowledge of students as shown from results of post-test analysis. More than $86 \%$ of the faculty members and $80 \%$ of the students rated CAL methodology more than 3 at Likert scale.

Conclusions: As compared to teaching by cards, the learning was enhanced by CAL. Students found CAL more enjoyable, interactive, comprehensible and easy to retain. In future, students would prefer CAL as an alternative method of learning in experimental laboratory.
\end{abstract}

Keywords: CAL, Experimental pharmacology, Feedback, Undergraduate students

\section{INTRODUCTION}

Teaching in pharmacology is predominantly lecture based. During pharmacology practical, teaching methodology includes animal experiments, clinical Pharmacy exercises, prescription writing, criticism of prescription and clinical problems. $^{1}$

Clinical implementation of pharmacy lab and experimental pharmacology exercises have always been questioned and criticised. ${ }^{2}$ Over the last decade, computers are being used 
widely in under graduate teaching and has made a significant impact.3Animal experiments have been restricted due to strict CPCSEA rules and regulations for procurement of animal and experimentation on them.

Presently, teaching is done by showing cards with tracings. This method only develops the cognitive domain and is not very interesting and interactive. Students find it difficult to correlate outcome of such learning with the practical use in the clinics. Learning outcome is less with the present method.

Because of ethical issues CAL is used as an alternative to animal experiments. CAL has the advantage of demonstration of experiments without killing animals and repetition of experiment. Today, CAL constitute a vital part in the pharmacology curriculum. Recent trends in the developments of information technology support such methods. ${ }^{4}$ Students of the current generation expects technology to be used in advancing their learning. There is a need to change the traditional passive learning methodologies to an active technology based experimental learning methodology. ${ }^{5}$ By demonstrating through software their psychomotor skill will be enhanced. In a review medical student have stated that they prefer Web tutorials rather than traditional lecture-based classes. Web based learning is an important tool in evidence-based medicine as it is a continually being developed and updated. ${ }^{6}$

Therefore, to enhance the learning and make teaching interactive and interesting we plan to introduce CAL and will compare it with present teaching methodology (cards). To know the perception and attitude of undergraduate students and faculty members toward CAL in experimental pharmacology their feedback will also be taken.

The objectives of the study are to assess and evaluate the learning outcome of two methods (teaching by showing cards and computer assisted) in experimental Pharmacology and to assess the perception of students and faculty towards implementation of CAL.

\section{METHODS}

A prospective interventional and comparative study was conducted among second professional undergraduate medical (UG) students of Saraswathi Institute of Medical Sciences (SIMS) in the Department of Pharmacology of the institution in Hapur during October 2016 to March 2017, India. Approval of Institution Ethical Committee (IEC) was taken. All students of regular batch of the second professional of UG medical course (MBBS) were eligible to participate in the study.

Faculty members of the department were sensitized through a workshop and questionnaire was given to the faculty to know their perception towards CAL (Annexure 1). Questionnaire for Post-test of both the modules and perception of the students for CAL were prepared and validated (Annexure II). Informed consent was taken from each study participant. Second year's undergraduate medical students $\left(4^{\text {th }}\right.$ semester) were randomly divided into two groups: group A and group B.

\section{Two modules were selected}

- Study of drugs on rabbit eye;

- Study of drugs on frog heart.

This was a cross over design wherein one group learned the first module with the use of traditional cards and another group learned the same module by the software.

For group A, cards were used for demonstration of the effect of drugs on rabbit eye and for group B, CAL method was used for demonstration. After a week, for group B, cards were used for the demonstration of effect of drugs on frog heart.

For group A, CAL method was used for demonstration of effect of drugs on frog heart. Thus, both groups were equally exposed to both modes of demonstrations. All the experiments were demonstrated by same teacher at interval of one week. For the second module, the participant's groups were cross over wherein the participant who were taught the first module with the cards learned the second module with the CAL method and vice versa.

After every module, test paper containing 10 multiple choice questions (MCQs) of 1 mark each was given to the participants. At the end of the study, participant's feedback was taken by giving them a questionnaire to elicit their perception about the effectiveness of CAL.

Feedback questionnaire consisted of 10 questions. $^{6}$ questions were on 5-point Likert scale, 3 questions were for yes or no, and last one was an open-ended question. The feedback was taken on the specific points like interactive, interesting, easy to understand, easy to retain, preference of participants to do practical. Open ended question included suggestions for further improvement in teaching methodologies in Pharmacology.

\section{RESULTS}

The results were analyzed on the basis of percentage of participants. For first module i.e. rabbit eye total attendance of participants were 45 .

They were divided in 2 groups randomly. For the experiment rabbit eye for traditional method i.e. by cards, out of 23 students 16 (69\%) students scored 6 or $>6$ marks (>60\%) for cards while for Computer assisted learning (CAL) total number of participants were 22 and out of them $16(72 \%)$ scored 6 or $>6$ (out of 10) marks (Table 1). For the second experiment i.e. Frog heart for traditional method by cards, out of 21 participants $17(80 \%)$ scored 6 or $>6$ 
marks (>60\%) for cards while for CAL total number of participants were 24 and out of them 23 students (90\%) scored 6 (out of 10) marks (Table 1).

Table 1: Comparison of marks obtained post-test.

\begin{tabular}{|c|c|c|c|c|}
\hline \multirow[b]{2}{*}{ Marks } & \multicolumn{2}{|c|}{ Rabbit eye } & \multicolumn{2}{|c|}{ Frog heart } \\
\hline & $\begin{array}{l}\text { CARD. } \\
23\end{array}$ & CAL-22 & $\begin{array}{l}\text { CARD- } \\
21\end{array}$ & CAL-24 \\
\hline 10 & - & - & - & 03 \\
\hline 09 & 07 & - & 07 & 07 \\
\hline 08 & 02 & - & 05 & 08 \\
\hline 07 & 04 & - & 02 & 04 \\
\hline 06 & 03 & 16 & 03 & 01 \\
\hline 05 & - & 04 & 01 & 01 \\
\hline 04 & 01 & 01 & 02 & - \\
\hline 03 & 04 & 01 & 01 & - \\
\hline 02 & 01 & - & - & - \\
\hline 01 & 01 & - & - & - \\
\hline
\end{tabular}

For first module i.e. Rabbit eye marks of post-test after traditional method by cards and CAL were compared. Pvalue was $0.31(>0.05)$. The difference was not significant statistically (Table 2). For the second experiment i.e. frog heart for traditional method by cards and CAL marks of post-test were compared and it was found that the difference was not significant statistically ( $p$-value was 0.75 (>0.05) (Table 2).

Table 2: Comparison of Cards and CAL teaching method.

\begin{tabular}{|lllll|}
\multirow{2}{*}{ Experiments } & \multicolumn{2}{c}{ Rabbit eye } & \multicolumn{2}{l|}{ Frog heart } \\
& Cards & CAL & Cards & CAL \\
\hline Mean & 2.2 & 3.15 & 2.75 & 3.14 \\
\hline SD & 1.7 & 1.95 & 2.19 & 2.54 \\
\hline P-value & $0.31(\mathrm{p}>0.05) \mathrm{NS}$ & $0.75(\mathrm{p}>0.05) \mathrm{NS}$ \\
\hline
\end{tabular}

Figure 1 shows the comparative finding of the performance of students in both the experiments (Rabbit eye and Frog heart) by traditional method and by using CAL. Students performed better by CAL method as compared to traditional card method of teaching.

The feedback was analyzed on the basis of percentage of faculty who rated the teaching methodology more than three on Likert scale. Most of the faculty members found CAL costly. Faculty found CAL method of teaching very useful.

The feedback was analyzed on the basis of percentage of students who rated three or more on Likert scale. They found CAL method better and easy to understand and retain. Students wanted CAL method to be used for teaching experimental pharmacology.

It was observed that $>86 \%$ of faculty rated CAL teaching method $>3$ on Likert scale. Faculty was in favor of installing computers in the lab to teach students by CAL. $>80 \%$ students rated $>3$ on Likert scale.

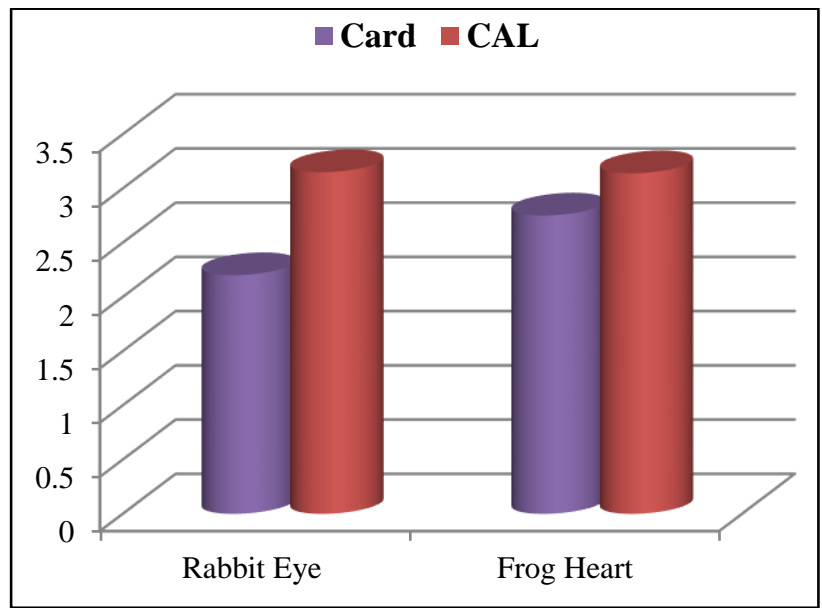

Comparison of post-test performance between two methods.

Figure 1: Comparison of performance of students.

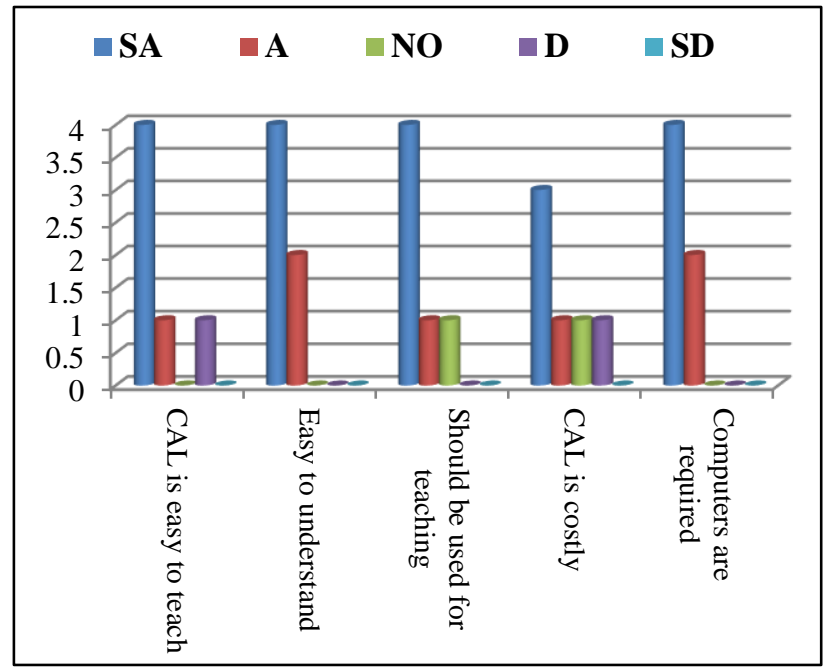

Figure 2: Faculty's perception (CAL).

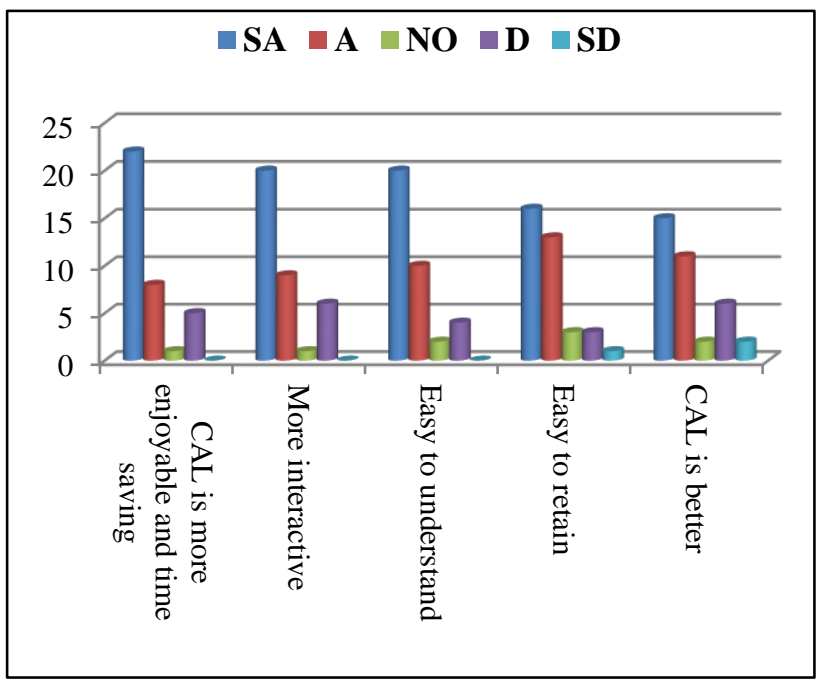

Figure 3: Students' perception (CAL). 
The last two direct questions with "yes" or "no" answer choices were asked in the feedback. The question asked the preference of method they would like to use in future for teaching and practical classes. More than $80 \%$ students opted CAL for future while $86 \%$ students preferred CAL teaching for conducting practical classes.

Table 3: Rating of CAL by students and faculty.

\begin{tabular}{|ll|}
\hline Participants & Score $>\mathbf{3}$ on likert scale (\%) \\
\hline Faculty & $>86 \%$ \\
\hline Students & $>80 \%$ \\
\hline
\end{tabular}

Percentage of faculty and students who rated CAL teaching methodology $>3$ on Likert scale.

\section{DISCUSSION}

Until the 1990s, experimental pharmacology practical classes were being performed by conducting practical teaching on animals and this method was the central feature of pharmacology teaching. The use of animals for educational purpose declined after the restrictions on animal killing by CPCSEA and many researchers also suggested that the need for using animals for education is small as compared to that with research. ${ }^{8}$ Guidelines of Ministry Of Social Justice Empowerment for the conduct of experiments on animals prohibit the use of animals for demonstrations and repetition of experiments just for obtaining skills. ${ }^{9}$ Medical Council Of India (MCI) has recommended CAL for practical teaching in Pharmacology and Physiology for undergraduate students. ${ }^{10}$

With CAL, many students can observe the effect at a time and can also repeat it to revise. CAL also has an advantage of promoting self-learning. The students are capable to follow the steps easily without help of any trained assistants, and the most importantly, the reduction, replacement and refinement of animal experiments can be achieved. ${ }^{11}$

After the ban on use of animal experimentation for undergraduate teaching, in majority of institutions, experimental pharmacology is being taught by using prepared charts, graphs, tracings etc. (conventional teaching). Such methods only develop the cognitive domain and are very interesting and interactive. Students find it difficult to correlate its use in the clinics. Learning outcome is less with the use of conventional methods. On the other hand, CAL meets the most of the learning objectives.

In present study authors compared traditional teaching with CAL in experimental pharmacology. Feedback of the faculty and students was taken for their perception. The results were analyzed on the basis of percentage of students (at least 50\%) who scored more than $60 \%$ marks. For the experiment Rabbit eye, for the traditional method i.e. by cards, $69 \%$ of students scored more than $60 \%$ marks while for CAL, $72 \%$ students scored more than $60 \%$ marks. The difference was not significant statistically.
For second experiment i.e. frog heart, for traditional method i.e. by cards, $80 \%$ students scored more than $60 \%$ marks while for CAL, $90 \%$ students scored more than $60 \%$ marks. The difference was not significant statistically.

With reference to student's feedback, $83 \%$ students found it time saving, interactive, easy to retain and also better understanding in terms of dose and concentration then by cards. Of all, $42 \%$ students preferred CAL over cards method and $75 \%$ students found CAL as a best alternative to traditional teaching. The present study results are very much similar to the study conducted by Badyal et al. ${ }^{12}$

Students wanted their teaching to be done by CAL but wanted their assessment to be done by cards as they were not trained to use computer.

Regarding perception of faculty $83 \%$ faculty found CAL easy to teach and easy to understand by the students. CAL should be used as teaching method in experimental labs. All faculty members (100\%) were in support of installation of computers in the laboratory before starting teaching by CAL. They suggested that undergraduate students should be trained on computers before starting CAL. They found it costly and were in favor of some subsidy and discount to be provided by companies to the Medical colleges.

The study was conducted by authors' laptops only as authors don't have computers in lab. The study could not be expanded for more experiments due to expiry of CAL software. Present results found CAL to be better than cards in many ways. If authors' want to teach by CAL a wellequipped CAL lab would be required.

The study can further be conducted for post graduate teaching as in post graduate teaching also animal experiments can be avoided just for practice of the procedure.

Limitations of this study includes few faculty members were not interested in teaching by CAL. They were comfortable in teaching by traditional method only. Due to non-availability of CAL lab it was difficult to teach students in small groups. To implement the CAL method of teaching there is need of CAL lab.

\section{CONCLUSION}

Learning of the students was enhanced by CAL as compared to teaching by cards. Students found it more enjoyable, interactive, comprehensible and easy to retain.

\section{Recommendations}

The study recommends the use of CAL as an alternative method of learning in experimental pharmacology for undergraduate medical students. In future, a large-scale study should be conducted to further validate the use of CAL. 
Funding: No funding sources

Conflict of interest: None declared

Ethical approval: The study was approved by the Institutional Ethics Committee

\section{REFERENCES}

1. Kamath A. A review of use of eLearning in pharmacology. Int $\mathrm{J}$ Integrative Med Sci. 2015;2(9):157-62.

2. Desai M. Changing face of pharmacology practicals for medical undergraduates. Indian J Pharmacol. 2009 Aug;41(4):151.

3. Brain S, Dewhurst DG, Williams AD. Evaluation of the usefulness of a computer-based learning program to support student learning in pharmacology. ALT-J. 1999 Jan 1;7(2):37-45.

4. Ahirwar M, Sinha A, Shakya A, Kumar V. Computer assisted learning in pharmacology: an update Alternatives to Animal Experiment Laboratory, Available at: https://pdfs.semanticscholar.org/96f8/b0688a5a38f6c 86bb1f141d918ac435b008e.pdf.

5. Rondon S, Sassi FC, de Andrade CR. Computer gamebased and traditional learning method: a comparison regarding students' knowledge retention. BMC Med Education. 2013 Dec;13(1):30.

6. Potomkova J, Mihal V, Cihalik C. Web-based instruction and its impact on the learning activity of medical students: a review. Biomed Pap Med Fac Univ Palacky Olomouc Czech Repub. 2006 Nov;150(2):357-61.
7. Chavda N, Yadav P, Chaudhari M, Kantharia ND. Second year student's feedback on teaching methodology and evaluation methods in Pharmacology. National Journal of Physiology, Pharmacy and Pharmacology. 2011;1(1):23-31.

8. John LJ. A review of computer assisted learning in medical undergraduates. J Pharmacol Pharmacotherapeut. 2013 Apr;4(2):86.

9. Anon. Government of India notifies the rules for breeding of and conducting animal experiments. Indian J Pharmacol. 1999;31:92-5.

10. Atray M, Agrawal A, Atray D. Comparative effectiveness of simulation based teaching versus conventional teaching for undergraduate students of second professional MBBS in experimental pharmacology. Int J Pharmaceut Sci Res. 2017 Mar $1 ; 8(3): 1492-7$.

11. Lexin W. Computer-simulated pharmacology experiments for undergraduate pharmacy students: experience from an Australian university. Ind $\mathbf{J}$ Pharmacol. 2001;33:280-2.

12. Badyal DK, Modgill V, Kaur J. Computer simulation models are implementable as replacements for animal experiments. Alternatives to laboratory animals: ATLA. 2009 Apr;37(2):191-5.

Cite this article as: Singh $\mathrm{S}$, Harshwarshan, Singh $\mathrm{V}$, Gupta B. Computer assisted learning module in experimental pharmacology for medical students: introduction and evaluation. Int $\mathrm{J}$ Basic Clin Pharmacol 2019;8:78-83. 


\section{ANNEXURE I}

\section{Faculty perception (CAL)}

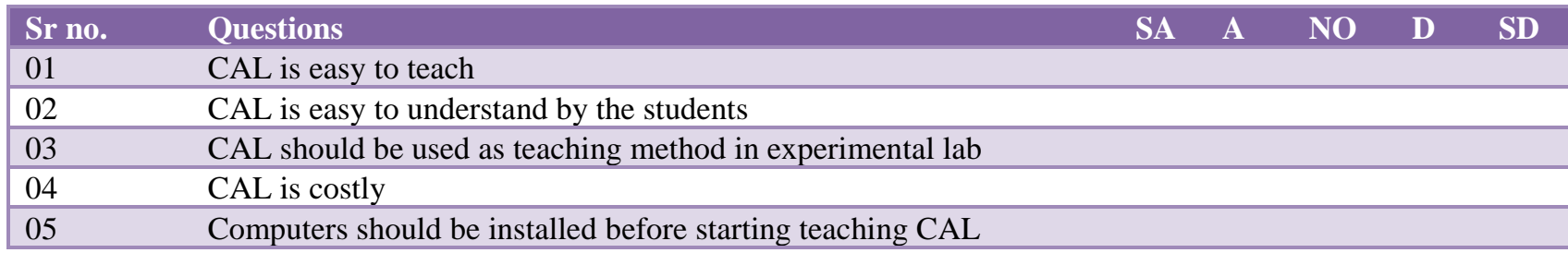

$\mathrm{SA}=$ Strongly Agree; $\mathrm{NO}=$ No of Opinion; $\mathrm{D}=$ Disagree; $\mathrm{SD}=$ Strongly Disagree.

Any other suggestions regarding CAL and experimental Pharmacology.

\section{ANNEXURE II}

Student questionnaire on CAL (Computer Assisted Learning) and laboratory based Pharmacological practical. (Feedback and perception)

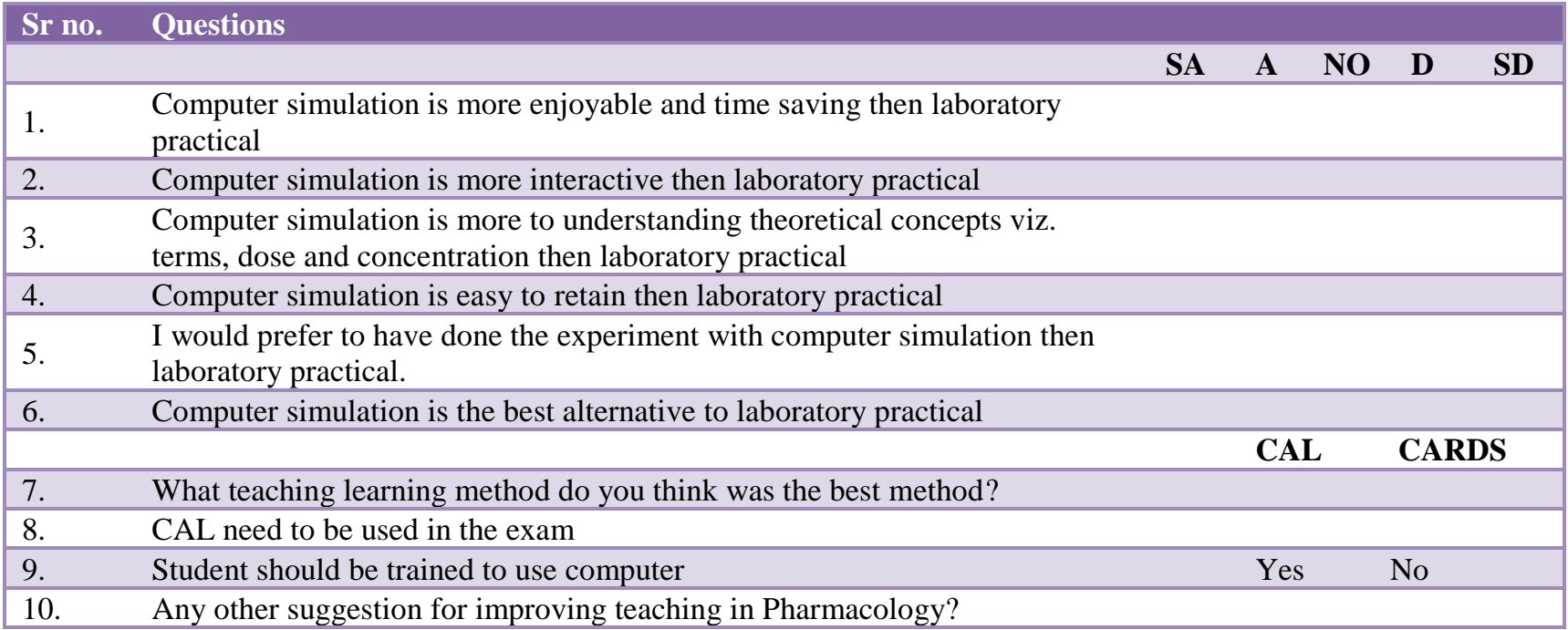

$\mathrm{SA}=$ Strongly Agree; $\mathrm{NO}=$ No of Opinion; $\mathrm{D}=$ Disagree; $\mathrm{SD}=$ Strongly Disagree. 